\title{
TU/e emonownen

\section{Groups III and V impurity solubilities in silicon due to laser, flash, and solid-phase-epitaxial-regrowth anneals}

\section{Citation for published version (APA):}

Duffy, R., Dao, T., Tamminga, Y., Tak, van der, K., Roozeboom, F., \& Augendre, E. (2006). Groups III and V impurity solubilities in silicon due to laser, flash, and solid-phase-epitaxial-regrowth anneals. Applied Physics Letters, 89(7), 071915-1/3. [071915]. https://doi.org/10.1063/1.2337081

DOI:

10.1063/1.2337081

Document status and date:

Published: 01/01/2006

\section{Document Version:}

Publisher's PDF, also known as Version of Record (includes final page, issue and volume numbers)

\section{Please check the document version of this publication:}

- A submitted manuscript is the version of the article upon submission and before peer-review. There can be important differences between the submitted version and the official published version of record. People interested in the research are advised to contact the author for the final version of the publication, or visit the $\mathrm{DOI}$ to the publisher's website.

- The final author version and the galley proof are versions of the publication after peer review.

- The final published version features the final layout of the paper including the volume, issue and page numbers.

Link to publication

\section{General rights}

Copyright and moral rights for the publications made accessible in the public portal are retained by the authors and/or other copyright owners and it is a condition of accessing publications that users recognise and abide by the legal requirements associated with these rights.

- Users may download and print one copy of any publication from the public portal for the purpose of private study or research.

- You may not further distribute the material or use it for any profit-making activity or commercial gain

- You may freely distribute the URL identifying the publication in the public portal.

If the publication is distributed under the terms of Article 25fa of the Dutch Copyright Act, indicated by the "Taverne" license above, please follow below link for the End User Agreement:

www.tue.nl/taverne

Take down policy

If you believe that this document breaches copyright please contact us at:

openaccess@tue.nl

providing details and we will investigate your claim. 


\title{
Groups III and V impurity solubilities in silicon due to laser, flash, and solid-phase-epitaxial-regrowth anneals
}

\author{
R. Duffy ${ }^{\mathrm{a})}$ \\ Philips Research Leuven, Kapeldreef 75, 3001 Leuven, Belgium \\ T. Dao, Y. Tamminga, K. van der Tak, and F. Roozeboom \\ Philips Research Laboratories Eindhoven, Prof. Holstlaan 4, 5656 AA Eindhoven, The Netherlands \\ E. Augendre \\ IMEC, Kapeldreef 75, 3001 Leuven, Belgium
}

(Received 26 April 2006; accepted 27 June 2006; published online 17 August 2006)

\begin{abstract}
In this work the authors studied impurity solubilities of groups III and V elements in silicon resulting from laser anneal, flash anneal, and solid-phase-epitaxial regrowth. Rutherford backscattering channeling analysis was used to determine substitutional impurity depth profiles generated from the difference between the random and aligned spectra. Despite the large difference in peak temperatures and times, the anneals produce similar results with maximum solubilities beating the maximum equilibrium values by one to two orders of magnitude depending on the impurity. The correlation between the metastable solubility and the equilibrium distribution coefficient allows a prediction of values for other impurities not extracted experimentally. (C) 2006 American Institute of Physics. [DOI: 10.1063/1.2337081]
\end{abstract}

In the 1940s and 1950s many equilibrium impurity solubilities in silicon were determined experimentally. In a review paper by Trumbore ${ }^{1}$ this body of work is nicely summarized, and the graph therein of impurity solubility versus temperature is frequently reproduced in textbooks. Aboveequilibrium levels of solubility, allowing for advanced device scaling and greater freedom for process optimization, are known to be generated by solid-phase-epitaxial-regrowth (SPER), flash, and laser anneals. By the early 1980s impurity solubilities due to SPER (Refs. 2 and 3) and full-melt laser anneals ${ }^{4}$ were reported. The aim of this work is to extract groups III and V impurity solubilities for flash anneal and for submelt laser anneal, advanced annealing techniques commonly used in industry. Also, we directly compare (1) SPER, (2) flash, and (3) sub-melt laser anneal by applying these annealing techniques to the same impurity profiles to determine which produces the highest solubilities.

Due to device scaling most junction formation techniques now involve amorphization of the silicon substrate, either in the form of self-amorphization during implantation of large-sized impurities or in the form of preamorphization with a silicon or germanium implantation to prevent channeling of small-sized impurities such as boron. An important physical parameter to consider when studying impurities in the post-recrystallization regime is the metastable solubility limit. Metastable solubility is higher than the maximum equilibrium solubility, as under the extremely nonequilibrium conditions just after recrystallization the silicon lattice can substitutionally incorporate a very high quantity of impurity atoms. With prolonged annealing metastable solubility returns to the equilibrium value, as impurities come out of substitutional positions. A clear example of this was demonstrated by Williams and Short ${ }^{5}$ for antimony profiles activated by SPER at $580{ }^{\circ} \mathrm{C}$ and postannealed at $700-1000{ }^{\circ} \mathrm{C}$.

\footnotetext{
${ }^{a)}$ Electronic mail: ray.duffy@philips.com
}

Experiments were performed using Czochralski-grown, $\langle 100\rangle$ oriented, $p$-type silicon wafers. Implants were performed to high doses to create impurity profiles with very high concentrations. Implant energies were such that the projected range of the impurity profile was not at the surface, thus reducing the influence of surface effects during processing and analysis. Arsenic was implanted to a dose of 4 $\times 10^{16} \mathrm{~cm}^{-2}$ with an energy of $30 \mathrm{keV}$. Antimony was implanted to a dose of $1 \times 10^{16} \mathrm{~cm}^{-2}$ with an energy of $90 \mathrm{keV}$. Bismuth was implanted to a dose of $1 \times 10^{16} \mathrm{~cm}^{-2}$ with an energy of $120 \mathrm{keV}$. These implants amorphize the silicon substrate. Anneals were then performed in an inert ambient. The SPER anneal was at $700{ }^{\circ} \mathrm{C}$ for $180 \mathrm{~s}$, which is longer than the usual SPER anneal, as retarded recrystallization rates were anticipated due to the extremely high impurity concentrations. ${ }^{6-8}$ The peak temperature for both flash and laser anneals was $1300^{\circ} \mathrm{C}$. Flash anneal had an intermediate temperature of $700{ }^{\circ} \mathrm{C}$.

Rutherford backscattering (RBS) channeling analysis was used to determine the substitutional impurity depth profiles and residual amorphous silicon layer thicknesses. The RBS analysis was performed with $2 \mathrm{MeV}$ helium ions. The incident beam was directed in the $\langle 100\rangle$ channeling direction, perpendicular to the silicon surface. The scattering angle for the outcoming helium ions was $100^{\circ}$, an exit angle of $10^{\circ}$ with the surface. Glancing exit angle RBS enhances the depth resolution. The depth scale was obtained by converting energy loss of the helium ions in the silicon to at. $/ \mathrm{cm}^{2}$ using the stopping cross sections as given by RUMP, the computer simulation program for RBS spectra. Dividing the at. $/ \mathrm{cm}^{2}$ quantity by the density of silicon $\left(4.98 \times 10^{22}\right.$ at. $\left./ \mathrm{cm}^{-3}\right)$ gives the layer thickness per eV. Multiplying the layer thickness per $\mathrm{eV}$ with the channel width in $\mathrm{eV}$, we derived the thickness per channel $(\mathrm{nm} / \mathrm{ch})$. RUMP showed that the variation in the depth per channel as a function of depth and as a function of element is less than $2 \%$. We used the mean value $(0.514 \mathrm{~nm} / \mathrm{keV})$ to obtain the depth scale of our impurity concentration plots. Substitutional profiles were generated 
from the difference between the random and aligned spectra. The total number of dopant atoms is determined from the integrated area under the profiles. The internal calibration in the spectra is the silicon random height. The number of counts in one channel leads to the number of dopant atoms per $\mathrm{cm}^{2}$. Thus by dividing this number by $\mathrm{nm} / \mathrm{ch}$, the concentration $\left(\right.$ at. $\left./ \mathrm{cm}^{3}\right)$ is calculated. The error in the concentration scale is less than $10 \%$.

Figure 1(a) shows substitutional arsenic versus depth profiles for the $4 \times 10^{16} \mathrm{~cm}^{-2}, 30 \mathrm{keV}$ implant after SPER, flash, and laser anneals. The maximum equilibrium solubility of $1.5 \times 10^{21} \mathrm{~cm}^{-3}$ is marked for comparison. ${ }^{1}$ For these samples RBS indicated 4-7 nm of residual amorphous silicon (i.e., not recrystallized) close to the surface after the anneals. All three advanced annealing approaches beat the maximum equilibrium value. In this case SPER generates the highest substitutionality with a peak at $9.6 \times 10^{21} \mathrm{~cm}^{-3}$. Flash anneal and laser anneal produce peak values of 2.9 $\times 10^{21}$ and $3.6 \times 10^{21} \mathrm{~cm}^{-3}$, respectively. Literature also indicates that SPER (Ref. 2) produces higher arsenic solubilities than full-melt laser anneal. ${ }^{4}$

Figure 1(b) shows substitutional antimony versus depth profiles for the $1 \times 10^{16} \mathrm{~cm}^{-2}, 90 \mathrm{keV}$ implant after SPER, flash, and laser anneals. The maximum equilibrium solubility is $7 \times 10^{19} \mathrm{~cm}^{-3}$. ${ }^{1}$ For these samples RBS indicated residual amorphous silicon depths of 13, 4.5, and $4.5 \mathrm{~nm}$ after SPER, flash, and laser anneals, respectively. All three advanced annealing approaches beat the maximum equilibrium value. SPER, flash, and laser anneals produce peak values of 6.4 $\times 10^{20}, 3.1 \times 10^{20}$, and $4.2 \times 10^{20} \mathrm{~cm}^{-3}$, respectively.

Figure 1(c) shows substitutional bismuth versus depth profiles for the $1 \times 10^{16} \mathrm{~cm}^{-2}, 120 \mathrm{keV}$ implant after SPER, flash, and laser anneals. The maximum equilibrium solubility is $8 \times 10^{17} \mathrm{~cm}^{-3}$. ${ }^{1}$ For these samples RBS indicated residual amorphous silicon depths of 67, 44, and $55 \mathrm{~nm}$ after SPER, flash, and laser anneals, respectively. All three advanced annealing approaches beat the maximum equilibrium value. SPER, flash, and laser anneals produce peak values of 9.4 $\times 10^{19}, 7.9 \times 10^{19}$, and $1.2 \times 10^{20} \mathrm{~cm}^{-3}$, respectively.

In Figs. 1(b) and 1(c) we observe that the metastable solubilities produced by the different anneals are largely similar relative to the maximum equilibrium values. This is a remarkable result as there is a $600{ }^{\circ} \mathrm{C}$ difference between the SPER anneal and the other two anneals. The anneal time for SPER is at least $10^{6}$ times longer than the laser anneal. This temperature independence of metastable solubility is in contrast to the well-established temperature dependence of equilibrium solubility.

Consider an alloy binary phase diagram of host material $\alpha$ (silicon) with impurity element $\beta$ (dopant) dissolved therein. Under equilibrium conditions the solid solubility limit is temperature dependent. After recrystallization, under metastable conditions, we have solid material $\alpha$ with higher concentrations of dissolved impurity $\beta$. Thus in phase diagram terms, the solid solubility limit is shifted along the composition axis towards higher $\beta$ content. Furthermore, based on our experimental data it is temperature independent across the range of $700-1300{ }^{\circ} \mathrm{C}$ for antimony and bismuth, and retrograde dependent for arsenic.

In our previous work ${ }^{9}$ we highlighted the correlation between metastable solubility and the equilibrium distribution coefficient $k$, which is defined as the relative tendency of various impurities to dissolve in solid silicon. Trumbore reDownloaded 21 Jun 2010 to 131.155.109.90. Redistribution subject
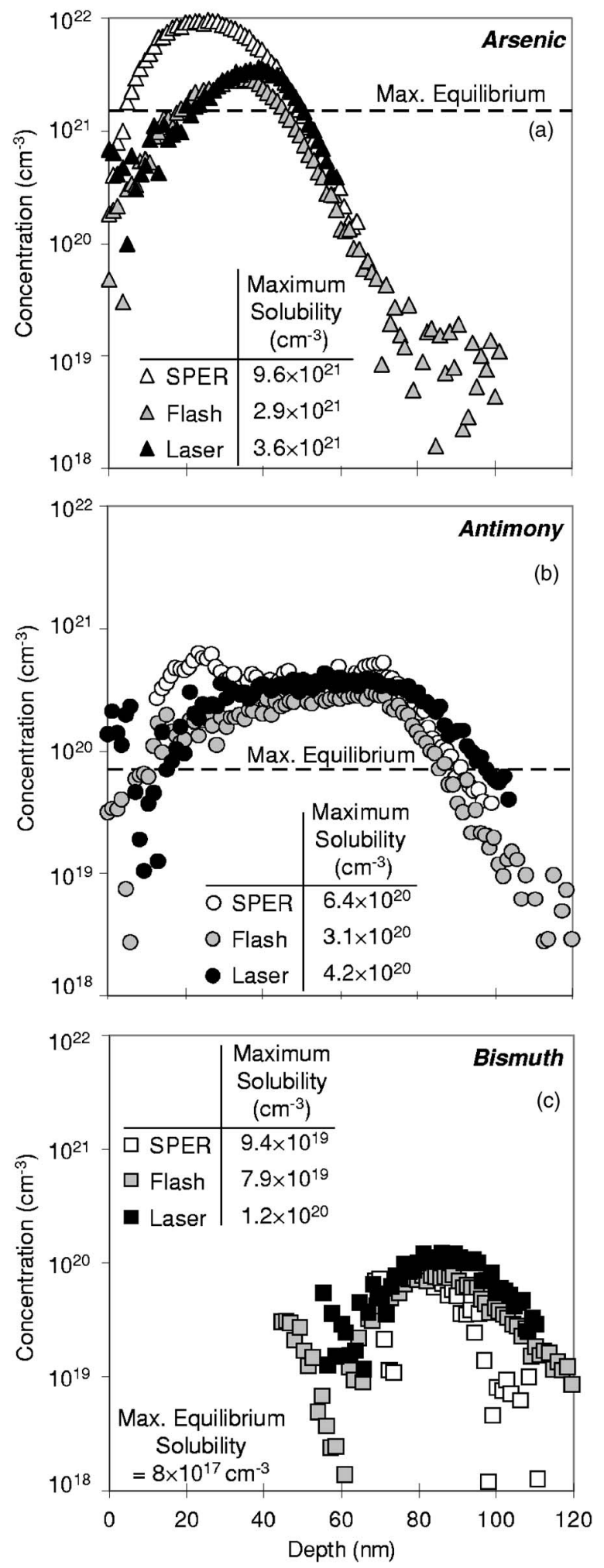

FIG. 1. Substitutional impurity vs depth profiles generated by RBS. The anneals were $700{ }^{\circ} \mathrm{C}, 180 \mathrm{~s}$ for SPER, and $1300^{\circ} \mathrm{C}$, submillisecond for flash and submelt laser anneals, all performed in an inert ambient. (a) Arsenic was implanted to a dose of $4 \times 10^{16} \mathrm{~cm}^{-2}$ with an energy of $30 \mathrm{keV}$. There is $4-7 \mathrm{~nm}$ of residual amorphous silicon close to the surface after the anneals. (b) Antimony was implanted to a dose of $1 \times 10^{16} \mathrm{~cm}^{-2}$ with an energy of $90 \mathrm{keV}$. There are residual amorphous silicon depths of 13, 4.5, and $4.5 \mathrm{~nm}$ after SPER, flash, and laser anneals, respectively. (c) Bismuth was implanted to a dose of $1 \times 10^{16} \mathrm{~cm}^{-2}$ with an energy of $120 \mathrm{keV}$. There are residual amorphous silicon depths of 67, 44, and $55 \mathrm{~nm}$ after SPER, flash, and laser anneals, respectively.

ports $k$ values for many impurities in silicon. ${ }^{1}$ In terms of concentrations, $k=C_{\text {solid }} / C_{\text {liquid }}$ at the melting point of sili-
to AlP license or copyright; see http://apl.aip.org/apl/copyright.jsp 


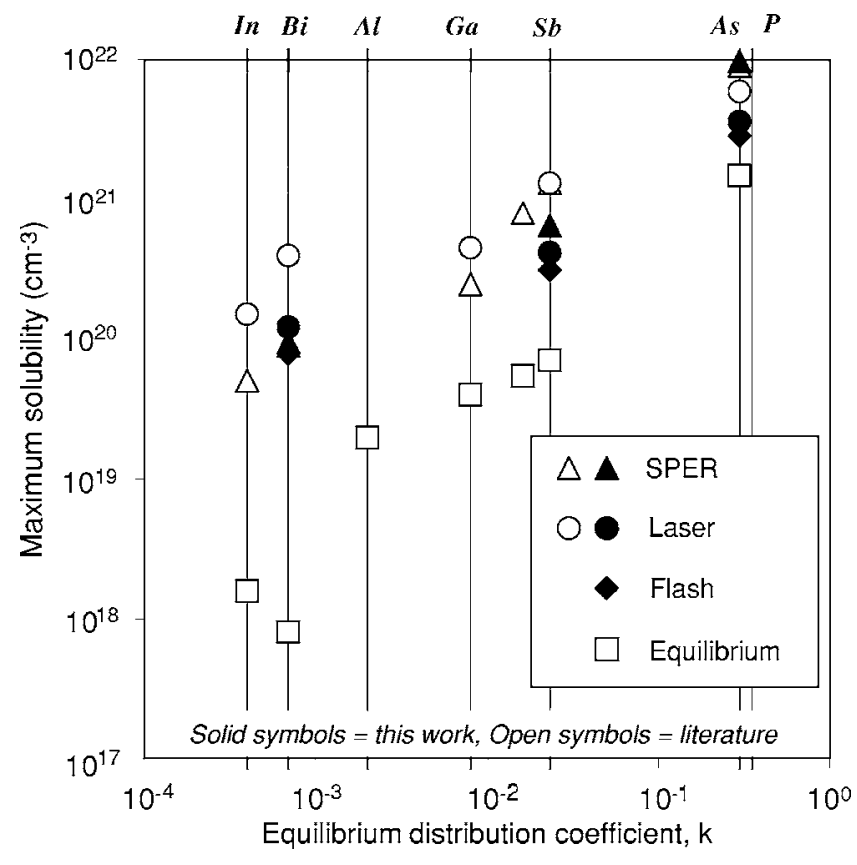

FIG. 2. Maximum solubility vs equilibrium distribution coefficient for groups III and V impurities in silicon. The solid symbols represent experimental data from this work for SPER, flash, and submelt laser anneals. The open symbols represent literature data for equilibrium conditions and SPER and full-melt laser anneals.

con. Thus if equilibrium solubility is high, $k$ is close to 1 . If equilibrium solubility is low, $k$ is significantly lower than 1 .

In Fig. 2 maximum solubility data extracted from Fig. 1 are plotted versus $k$. Relevant literature data for equilibrium conditions $^{1,10}$ and SPER (Refs. 2 and 3) and full-melt laser ${ }^{4}$ anneals are also included. The data values can be found also in Table I. Metastable solubility is higher than the corresponding equilibrium value. The benefit of switching to advanced anneals is greater for larger sized impurities such as indium and bismuth. The full-melt laser data of White et al. ${ }^{4}$ appear to beat the other techniques, at least for impurities

TABLE I. Maximum solubilities of groups III and V impurities in silicon under equilibrium conditions and after SPER, flash, and laser anneals.

\begin{tabular}{|c|c|c|c|c|c|}
\hline Impurity & Type & Equilibrium & SPER & Flash & Laser \\
\hline $\mathrm{P}$ & $n$ & $1.3 \times 10^{21 \mathrm{a}}$ & $\gg 10^{21^{b}}$ & $\gg 10^{21 \mathrm{~b}}$ & $\gg 10^{21^{b}}$ \\
\hline As & $n$ & $1.5 \times 10^{21 \mathrm{a}}$ & $\begin{array}{l}9.6 \times 10^{21 \mathrm{c}} \\
9.0 \times 10^{21 \mathrm{~d}}\end{array}$ & $2.9 \times 10^{21 \mathrm{c}}$ & $\begin{array}{l}3.6 \times 10^{21 \mathrm{c}} \\
6.0 \times 10^{21 \mathrm{e}}\end{array}$ \\
\hline $\mathrm{Sb}$ & $n$ & $7.0 \times 10^{19 a}$ & $\begin{array}{l}6.4 \times 10^{20 \mathrm{c}} \\
1.3 \times 10^{21 \mathrm{~d}}\end{array}$ & $3.1 \times 10^{20 c}$ & $\begin{array}{l}4.2 \times 10^{20 \mathrm{c}} \\
1.3 \times 10^{21 \mathrm{e}}\end{array}$ \\
\hline $\mathrm{Bi}$ & $n$ & $8.0 \times 10^{17 a}$ & $\begin{array}{l}9.4 \times 10^{19 c} \\
9.0 \times 10^{19 d}\end{array}$ & $7.9 \times 10^{19 c}$ & $\begin{array}{l}1.2 \times 10^{20 \mathrm{c}} \\
4.0 \times 10^{20 \mathrm{e}}\end{array}$ \\
\hline $\mathrm{Al}$ & $p$ & $2.0 \times 10^{19 a}$ & $2.0 \times 10^{20 \mathrm{~b}}$ & $1.0 \times 10^{20 \mathrm{~b}}$ & $2.0 \times 10^{20 \mathrm{~b}}$ \\
\hline $\mathrm{Ga}$ & $p$ & $4.0 \times 10^{19 a}$ & $\begin{array}{l}5.5 \times 10^{20 \mathrm{~b}} \\
2.5 \times 10^{20^{\mathrm{f}}}\end{array}$ & $3.0 \times 10^{20 b}$ & $\begin{array}{l}4.0 \times 10^{20 \mathrm{~b}} \\
4.5 \times 10^{20 \mathrm{e}}\end{array}$ \\
\hline $\ln$ & $p$ & $1.6 \times 10^{18 g}$ & $\begin{array}{l}6.0 \times 10^{19 b} \\
5.0 \times 10^{19 d}\end{array}$ & $5.0 \times 10^{19 b}$ & $\begin{array}{l}7.0 \times 10^{19 \mathrm{~b}} \\
1.5 \times 10^{20 \mathrm{e}}\end{array}$ \\
\hline
\end{tabular}

${ }^{\mathrm{a}}$ Reference 1 .

${ }^{\mathrm{b}}$ This work (estimated from trendline).

${ }^{\mathrm{c}}$ This work (experiment).

${ }^{\mathrm{d}}$ Reference 2 .

${ }^{\mathrm{e}}$ Reference 4.

${ }^{\mathrm{f}}$ Reference 3 .

${ }^{\mathrm{g}}$ Reference 10 . other than arsenic. This difference is currently not understood as flash, submelt laser, and full-melt laser anneals all melt and recrystallize the amorphous silicon within a submillisecond time frame, leading to largely similar regrowth conditions. However, it is difficult to make a fair comparison without processing the same impurity profile.

Returning again to the correlation between metastable solubility and $k$, we fitted a trendline to each set of experimental data. For clarity these trendlines are not included in Fig. 2 (see Fig. 15 in Ref. 9 for an example). Using these we extracted the metastable solubilities for impurities not investigated experimentally. The extracted values are shown in Table I. With respect to metal-oxide-semiconductor device applications, advanced anneals can facilitate the potential of impurities not useful under equilibrium conditions. For example, with source and drain regions typically requiring concentrations $>10^{20} \mathrm{~cm}^{-3}$, antimony and gallium could be candidates under metastable conditions. Channel and pocket doping concentrations can reach $\sim 5 \times 10^{18} \mathrm{~cm}^{-3}$, thus bismuth and indium could be useful with SPER, flash, and laser anneals. Note that solubility does not guarantee electrical activity, but it is generally understood that nonsubstitutional impurities will not contribute to the electrical behavior of the device.

The arsenic data of Fig. 1(a) deserve further comment in relation to the work of Pawlak et al., ${ }^{11}$ where increased ramp rates for $700{ }^{\circ} \mathrm{C}$ anneals produced higher substitutionality. As stated previously, with prolonged annealing metastable solubility returns to the equilibrium value. In other words metastable solubility is created during recrystallization and destroyed with additional energy added to the system after recrystallization. Thus with faster ramp rates, with fixed peak temperature and hold time, the overall energy input is reduced, and thus the destructive postrecrystallization energy input is lower.

In summary, we studied impurity solubilities of groups III and V elements in silicon resulting from SPER, flash, and laser anneals. By applying these advanced anneals to the same impurity profiles, we were able to make a direct comparison between the different approaches. Despite the large difference in anneal temperatures and times they produce similar results, with maximum solubilities beating the maximum equilibrium values by approximately one to two orders of magnitude.

The authors would like to acknowledge Applied Materials for laser anneal support, and Mattson for flash anneal support.

${ }^{1}$ F. A. Trumbore, Bell Syst. Tech. J. 39, 205 (1960).

${ }^{2}$ J. S. Williams, Nucl. Instrum. Methods Phys. Res. 209/210, 219 (1983).

${ }^{3}$ J. Narayan and O. W. Holland, Appl. Phys. Lett. 41, 239 (1982).

${ }^{4}$ C. W. White, S. R. Wilson, B. R. Appleton, and F. W. Young, Jr., J. Appl. Phys. 51, 738 (1980).

${ }^{5}$ J. S. Williams and K. T. Short, J. Appl. Phys. 53, 8663 (1982).

${ }^{6}$ J. S. Williams and R. G. Elliman, Nucl. Instrum. Methods 182/183, 389 (1981).

${ }^{7}$ Y. Tamminga and W. J. M. J. Josquin, Appl. Phys. Lett. 32, 13 (1978).

${ }^{8}$ J. S. Williams and R. G. Elliman, Appl. Phys. Lett. 37, 829 (1980).

${ }^{9}$ R. Duffy, V. C. Venezia, K. van der Tak, M. J. P. Hopstaken, G. C. J. Maas, F. Roozeboom, Y. Tamminga, and T. Dao, J. Vac. Sci. Technol. B 23, 2021 (2005).

${ }^{10}$ W. Scott and R. J. Hager, J. Electron. Mater. 8, 581 (1979).

${ }^{11}$ B. J. Pawlak, R. Duffy, T. Janssens, W. Vandervorst, K. Maex, A. J. Smith, N. E. B. Cowern, T. Dao, and Y. Tamminga, Appl. Phys. Lett. 87, 031915 (2005). 